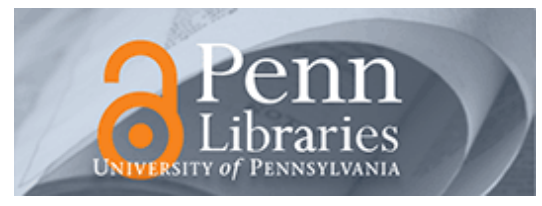

University of Pennsylvania

ScholarlyCommons

GSE Faculty Research

Graduate School of Education

January 2003

\title{
Accomplishing Identity in Participant-Denoting Discourse
}

\author{
Stanton Wortham \\ University of Pennsylvania, stanton.wortham@bc.edu
}

Follow this and additional works at: https://repository.upenn.edu/gse_pubs

\author{
Recommended Citation \\ Wortham, S. (2003). Accomplishing Identity in Participant-Denoting Discourse. Retrieved from \\ https://repository.upenn.edu/gse_pubs/50
}

Published as Journal of Linguistic Anthropology, Volume 13, Issue 2, 2003, pages 189-210. @ 2003 by the Regents of the University of California/American Anthropological Association. Copying and permissions notice: Authorization to copy this content beyond fair use (as specified in Sections 107 and 108 of the U.S. Copyright Law) for internal or personal use, or the internal or personal use of specific clients, is granted by the Regents of the University of California/on behalf of the American Anthropological Association for libraries and other users, provided that they are registered with and pay the specified fee via Rightslink ${ }^{\circledR}$ on Caliber (http://caliber.ucpress.net/)/AnthroSource (http://www.anthrosource.net) or directly with the Copyright Clearance Center, (http://www.copyright.com ).

This paper is posted at ScholarlyCommons. https://repository.upenn.edu/gse_pubs/50

For more information, please contact repository@pobox.upenn.edu. 


\title{
Accomplishing Identity in Participant-Denoting Discourse
}

\author{
Abstract \\ Individuals become socially identified when categories of identity are used repeatedly to characterize \\ them. Speech that denotes participants and involves parallelism between descriptions of participants and \\ the events that they enact in the event of speaking can be a powerful mechanism for accomplishing \\ consistent social identification. This article describes how two different types of participant-denoting \\ speech events-participant examples and autobiographical narratives-can involve such parallelism, in \\ which speakers simultaneously represent and enact analogous social positions and thereby strengthen \\ social identification.

\section{Comments} \\ Published as Journal of Linguistic Anthropology, Volume 13, Issue 2, 2003, pages 189-210. (c) 2003 by the \\ Regents of the University of California/American Anthropological Association. Copying and permissions \\ notice: Authorization to copy this content beyond fair use (as specified in Sections 107 and 108 of the \\ U.S. Copyright Law) for internal or personal use, or the internal or personal use of specific clients, is \\ granted by the Regents of the University of California/on behalf of the American Anthropological \\ Association for libraries and other users, provided that they are registered with and pay the specified fee \\ via Rightslink® on Caliber (http://caliber.ucpress.net/)/AnthroSource (http://www.anthrosource.net) or \\ directly with the Copyright Clearance Center, (http://www.copyright.com ).
}




\section{Accomplishing Identity in Participant-Denoting Discourse}

Individuals become socially identified when categories of identity are used repeatedly to characterize them. Speech that denotes participants and involves parallelism between descriptions of participants and the events that they enact in the event of speaking can be a powerful mechanism for accomplishing consistent social identification. This article describes how two different types of participant-denoting speech events-participant examples and autobiographical narratives-can involve such parallelism, in which speakers simultaneously represent and enact analogous social positions and thereby strengthen social identification.

$\mathrm{H}$ ow do individuals become socially and personally meaningful types of people? The explicit and implicit categories that identify an individual come from the social world. Just as any speaker has to "rent" the words he or she uses from the already-used set of words available in a community (Bakhtin 1981), the categories that identify individuals come from the community. But how do particular categories come consistently to identify a given individual?

Despite the common intuition that social identities are relatively stable, it has become clear that the stability of "objects" like culture and identity is instead accomplished as part of ongoing social processes (Bickhard and Christopher 1994; Bourdieu 1977; Csordas 1994; Urban 2001). At least three types of processes are relevant to explaining the accomplishment of social identification (Cole 1996; Lemke 2000). First, categories of identity circulate through communities over social-historical timescales and thereby become available to identify individuals. Second, individuals develop identities over ontogenetic time, by consistently adopting and/or getting assigned such categories. Third, both social categories and individual trajectories exist empirically only in particular events of identification, when categories come to identify 
participants. Social identification depends ultimately on the ratified presupposition, within performed interaction, of circulating categories of identity (Kulick 2000; Silverstein 1993).

This article argues that a particular type of speech event can be a powerful mechanism for accomplishing social identification. This type of event facilitates the consistent application of circulating sociohistorical categories to individuals. In participant-denoting speech events, at least one participant is explicitly denoted-for instance as a character in a story or an example. Sometimes a story or example both explicitly denotes participants in the speech event and allows them to enact relationships parallel to the ones denoted. Such parallelism between denoted content and enacted relationships can help accomplish stable social identification for an individual because the denotational/interactional parallelism yields more robust presupposition of identities and events than normally occurs in everyday interaction. I describe how two different types of participant-denoting speech events can involve such parallelism, whereby speakers simultaneously represent and enact analogous social positions. I argue that just as parallelism across media in ritual events can foster the consistent circulation of cultural patterns (Kratz 1994; Parmentier 1997), parallelism in participant-denoting discourse can help accomplish consistent social identification.

\section{Circulating Metadiscourses}

Mature sciences have made a transition from ontologies of substance to ontologies of process (Bickhard and Christopher 1994; Lemke 2000). Instead of positing objects or essences-like "phlogiston" or a "vital force"-to explain phenomena, we now realize that these apparent objects are in fact stabilities of organization within processes. Simply positing objects is easier, since one notices a stable pattern and "explains" it by proposing an object or essence. But this short-circuits genuine explanation, failing to uncover the processes that produce stabilities of organization. If this insight applies to the human sciences-and along with others I argue that it generally does (e.g., Bickhard and Christopher 1994; Bourdieu 1977; Csordas 1994; Merleau-Ponty 1962; Urban 2001)-many of our cherished concepts should be seen as place-holders, demanding further explanation. "Culture," "identity," "knowledge," "power," "self" and the like can more fruitfully be conceived as stabilities of organization within processes that we do not yet understand fully.

How do the self-organizing, open systems that produce culture, self, and so on maintain stabilities over time? This article sketches one answer for social identity. Social identification can be stabilized, such that an individual is consistently identified in characteristic ways, in part through parallelism between denotation and enactment in participant-denoting discourse. Such parallelism in particular events brings together circulating sociocultural concepts of identity with ontogenetic trajectories of participation across events, in a way that helps stabilize an individual's social identification. In order to describe how social identification can be stabilized in part through denotational and interactional parallelism in participant-denoting discourse, this section sketches a process-based account of culture and next sketches a process-based account of individual identification.

In his process-based account of culture, Urban $(1996,2001)$ describes the circulation of culture across individuals and groups. Culture takes material form as it circulates, getting communicated from one individual or group to another through 
sign vehicles, like oral or written speech, visual representations, or physical artifacts. The material vehicles disappear or cease to communicate, but culture continues as it circulates farther through other vehicles and into other spaces. Through inertia, culture tends to stay in motion-people will often continue to circulate an idea or pattern just because it is there, or out of habit. But there are also entropic forces that make uninterrupted circulation difficult, like physical degradation, mistakes, and lack of usefulness. So what explains the continued circulation of culture in recognizable forms?

Urban's (2001) answer to this question is: "metaculture." This concept is derived from the notion of "metadiscourses" (Silverstein and Urban 1996; Urban 1996), which has its roots in discussions of "frames" (Bateson 1972; Goffman 1974; Wittgenstein 1953). Metaculture is culture about culture, and metadiscourses are discourses about discourses. Members of any society explicitly and implicitly recognize many types of events. Metadiscourses are the explicit and implicit framings available in a given society for understanding social events as coherent. When confronted with an ongoing event, people will understand it as coherent when the (largely indexical) signs that compose it come increasingly to presuppose that a particular type of event is going on (Silverstein 1992). Social life can only be coherent insofar as metadiscourses are available for understanding the types of events that typically exist and the types of people who characteristically participate in them.

So culture continues to circulate in recognizable form because it is regimented or framed by certain metadiscourses. But this is not a one-way process. Because any bit of culture only has meaning as it becomes framed by metadiscourses, metadiscourses sometimes seem preeminent. Especially when the relationship between cultural signs and metadiscourses is "denotationally explicit" and "reportive" (Silverstein 1993:40)-that is, when one utterance segment explicitly describes the relevant metadiscourse for understanding another segment - the metadiscourse seems to be doing the important work. But in fact cultural stabilities involve active contributions from both circulating discourses and metadiscourses (Agha in press; Silverstein 1993; Urban 2001), or behaviors and systems of value (Bourdieu 1998). Metadiscourses do frame cultural signs, but cultural signs also presuppose and entail metadiscourses. Even denotationally explicit metadiscourses only take hold as indexical cues come to presuppose the metadiscourse. Silverstein $(1976,1992)$, Wortham (2001), and contributors to Hill and Irvine (1992) and Silverstein and Urban (1996) all describe how patterns of indexical cues can emerge and cohere, so as to establish a plausible metadiscursive frame for the event. Culture circulates in consistent ways, then, because of a dialectic between indexical cues that signal relevant metacultural frames and metacultural frames that regiment or disambiguate indexical cues.

Metadiscourses are most often denotationally implicit, such that patterns of indexical cues signal the type of event going on. Speakers and audience generally do not denote what they are doing to and with each other. Instead, they use various cues to signal the interactional event they are enacting. Silverstein (1993:40) describes such cases as "reflexive calibration," where one or more utterances metadiscursively regiment themselves, as it were, through largely nondenotational signs that index the relevant metadiscourse. The clearest cases of reflexive calibration involve poetic patterns of indexical cues, which collectively presuppose a particular metadiscourse as the one relevant to interpreting the utterances (Hymes 1996; Jakobson 1960; Silverstein 1985; Wortham 2001). In many cases speakers orient to such indexical cues and the 
metadiscourse they presuppose without consciously recognizing or explicitly articulating the metadiscourse organizing their interaction.

The capacity to catch the meaning of a reflexively calibrated event resembles the prereflective capacities to perceive and interpret described by phenomenologists (Bourdieu 1977; Csordas 2002; Dreyfus and Rabinow 1993; Merleau-Ponty 1962). Meaningful perception and social understanding depend on an unformulated practical grasp of the world. Explicit representations are sometimes important, but they are like islands in a sea of unformulated background dispositions (Taylor 1991). Successful reflexively calibrated language use can usefully be understood in phenomenological terms (Hanks 1993). When one catches the meaning of a discursive event, attending to the indexical cues that signal a relevant metadiscourse, it is like dancing smoothly with a partner or reacting appropriately in a sport. So an adequate account of how denotationally implicit metadiscourses circulate will cite the sorts of embodied dispositions described by phenomenologists.

In order to understand how culture comes to circulate in stable ways, then, we must study metaculture and metadiscourses. But this does not mean simply studying explicit metaculture. Culture circulates consistently as metadiscursive frames, and patterns of cultural signs or discursive cues cohere in recognizable ways. We must explore how tacit, embodied metadiscourses both get presupposed by and regiment discursive cues in a consistent way.

Many have argued that ritual is the quintessential means for producing the consistent circulation of metadiscourses (e.g., Du Bois 1986; Durkheim 1965; Kratz 1994; Malinowski 1935; Urban 1996). Rituals centrally involve parallelism. Ritual representations and enactments occur across multiple media: linguistic, bodily, visual, interactional, and so on (Csordas 1994; Kratz 1994; Parmentier 1997). Ritual events often involve repetition, with similar patterns repeated in parallel across media. A physical symbol of the social separation between men and women, for instance-like a diagram displayed during the ritual-may run parallel to the separate physical location of men and women in the event, and this may run parallel to the different forms of speech they contribute. Ritual can maintain and redirect the consistent circulation of metadiscourses in part because ritual events layer parallel metadiscourses or organizations of relationships across several media. Not only does ritual repeat patterns from one event to the next, but it also contains concurrent repetition of patterns within a given event, across media, through parallelism. The recurrence of analogous metacultural frames across media helps establish more consistent circulation of culture and metaculture.

Culture persists as it circulates through many events, events in which metadiscourses frame it consistently. Ritual or ritualized parallelism helps produce stable circulation of metadiscourses by bringing together mutually reinforcing metadiscursive frames and patterns of indexical cues.' The next section describes how some participant-denoting speech events involve ritualized parallelism, which helps produce stable social identities for individuals. Metadiscourses can come consistently to frame individuals' participation across a series of events, through ritualized participantdenoting discourse that involves parallelism across represented and enacted roles. 


\section{Stabilizing Individual Identification}

Because the social identification of individuals depends in part on circulating cultural categories of identity, a process-based account of social identification must explore circulating metadiscourses of identity. A metadiscourse of identity frames individual characters or participants as having a recognizable identity. For an individual to be consistently identified, some metadiscourse of identity must circulate consistently through events involving that individual. The circulation of the particular metadiscourse of identity must consistently overlap with the individual's trajectory of participation, across many events, such that his or her social identity stabilizes. An individual may come consistently to be identified in one way, in an institutional context that can also solidify as individuals get appropriately identified. Holland and Lave (2001) describe this process as the "thickening" of identity.

But given the various categories of identity that any individual could enact in a given context, how do individuals come consistently to be identified as recognizable types of persons? At the sociohistorical time scale, cultural categories of identity stabilize and become routinely available when certain metadiscourses come consistently to frame interactional events as involving similar roles and relationships. Similarly, for an individual's social identity to stabilize or thicken, metadiscourses of identity must consistently circulate to organize events in which the individual participates. At a mesolevel or ontogenetic time scale, individuals come to have a consistent trajectory of identification when the same metadiscourses are used to identify them across events. But what stabilizes these metadiscourses of identity, such that they consistently circulate through events involving the same individual?

Holland and Lave (2001), despite their useful account of how sociohistorical categories can identify individuals in practice, do not give a specific answer, saying merely that habitual local practices establish stable social identification. One answer that I propose here is that the consistent circulation of metadiscourses of identity can be established in part through a distinctive sort of participant-denoting discourse. Individuals' identities become stabilized through events in which a participant both gets represented as and enacts a particular identity. Participant-denoting discourse that involves this kind of parallelism produces stability in individuals' identities, in much the same way that ritual parallelism helps produce consistently circulating cultural patterns. Just as rituals often involve repetition of parallel patterns across media, some participant-denoting discourse involves parallelism and thus helps establish consistently circulating metadiscourses of identity. The parallel use of similar metadiscourses makes a particular social identification more robust and more likely to be presupposed in future events.

Certain sorts of participant-denoting discourse-like autobiographical narratives, for example-involve the doubling of participant roles, whereby some participants are both represented as characters in the narrative and also participate in the interactional event of narration. Sometimes events that involve such doubled roles contain parallelism across the content denoted and the event enacted (Wortham 1994, 1997. 2001). In other words, participants' characters, as denoted in a story, sometimes occupy roles parallel to those that the participants enact in the storytelling event itself. An autobiographical narrator, for instance, might represent herself as having adopted a certain role while also enacting a parallel role in the speech event. I argue that this sort of doubled-role participant-denoting discourse is a powerful mechanism for establishing the consistent circulation of metadiscourses of identity. 
Parallelism across denoted and enacted roles involves iconism across what Silverstein (1993:36-37) calls "denotational text" and "interactional text." Denotational and interactional text are two types of metadiscursive models that analysts and participants use to understand the segments of a discursive interaction as recognizable components of some established type of speech event. When we understand a discursive interaction as a denotational text, we model the linguistic expressions that compose that interaction as having referential and predicational values that contribute to some coherent message. When we understand a discursive interaction as an interactional text, we model its components as a series of utterances that compose a recognizable type of interaction. The analyses below show how denotational and interactional text sometimes run parallel in events of participant-denoting discourse.

Such parallelism can occur in at least two types of participant-denoting discourseparticipant examples (Wortham 1994) and autobiographical narratives. The doubling of denoted and enacted roles in such events facilitates parallelism between denotational and interactional texts. Sometimes the same social positioning described as part of the denotational text comes to organize the participants' interaction itself, as part of the interactional text. ${ }^{2}$ I have uncovered this sort of parallelism in separate research studies focused on different types of discourse-academic classroom discourse (Wortham 1994) and personal narrative (Wortham 2001). The existence of complex parallelism in these two distinct types of discourse may indicate a more general process. I argue here that such parallelism may recur because it helps produce the consistent circulation of metadiscourses of identity. Just as ritual events can keep characteristic metadiscourses circulating consistently in a group, parallelism in participant-denoting discourse can keep metadiscourses of identity circulating consistently along particular individuals' ontogenetic trajectories.

\section{Enacted Participant Examples}

As Rampton (in press) and others (e.g., McLaren 1986) have shown, classroom interactions are often ritualized. This section illustrates how classroom participant examples can involve a complex type of ritualization-parallelism between denotational and interactional texts. In a participant example, participants in the speech event get cast as characters in an example (Wortham 1994). These participants then have two roles, as a character in the example and as a participant in the discursive interaction. Participant examples occurred approximately once every 15 minutes in the high-school literature and history class discussions I studied. More often than one might expect, participants come to act like the characters they have been assigned through the example, thus creating parallelism between denotational and interactional texts (Wortham 1994, 1997).

The following participant example occurred in a ninth-grade history class described at length in Wortham (1994). The class has read Cicero's letter to Atticus, in which Cicero ponders what he should do about the tyranny of Caesar and the plot to overthrow him. Should he tell Caesar? Should he join the plotters? Or should he just keep quiet? In this respect, the text denotes a three-part role structure in Rome: Caesar-the-tyrant, those plotting against him, and Cicero stuck in between the two. The teacher (Mr. Smith or T/S) places a student (Maurice, or MRC) in a hypothetical situation analogous to Cicero's and asks him what he would do. (In the transcript. STS refers to the other students in the class.) - 
T/S: $\quad$ Maurice let's give a good example, you'll love this. Suppose this dictator, me. there was a plot going on. and you found out about it. and you knew it was gonnait's existing (3.0) among the people you knew. would you tell me. (5.0)

MRC: you said they know about it.

T/S: the plotters, against me. they're planning to push me

155

STS: down the stairs. [ and you know about it

T/S: now we all know Maurice and I have ha(hh)d arguments all year. would you tell me about it.

MRC: well- I might but uh what if they- what if they found 160 out that I told you then they want to kill me. (5.0) so I'm putting myself in trouble to save you, and I'm not going to do it.

STS: hnh hahahaha

Read for its contribution to the denotational text, the example describes a role structure analogous to that in Rome: Mr.-Smith-the-tyrant, the conspirators plotting to push him down the stairs, and Maurice the (hypothetical) potential informer stuck between the two. This is a participant example because some participants in the speech event itself (Mr. Smith and Maurice) now have a second role within the example.

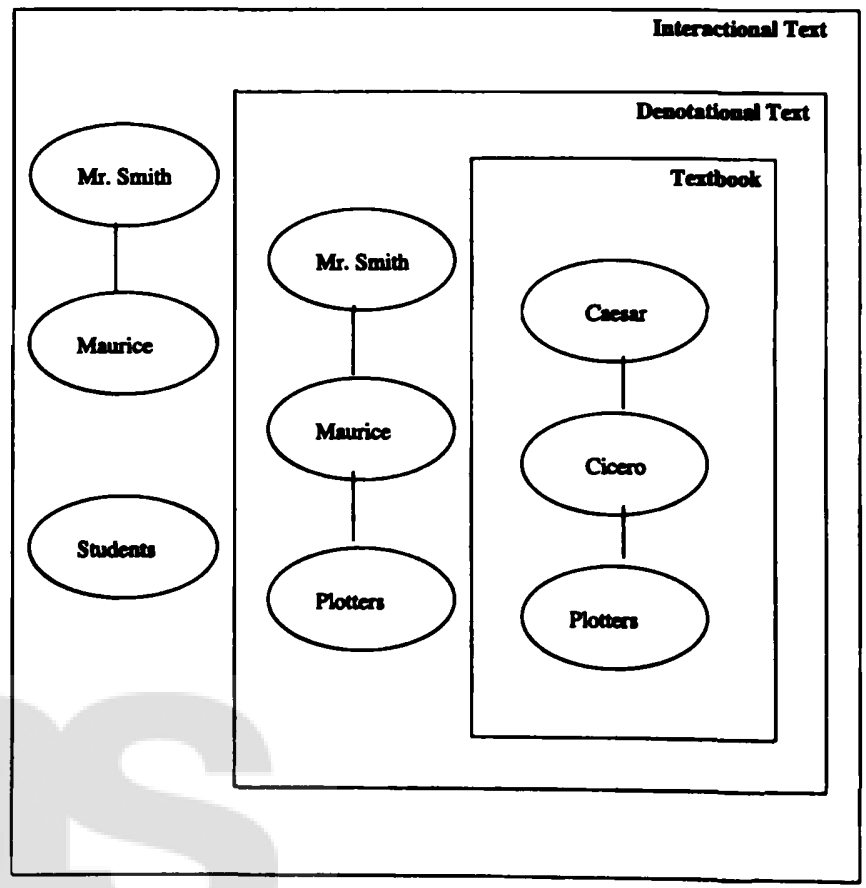


Figure 1 represents the salient characters at this point in the discursive interaction. In the two embedded rectangles, representing the denotational text, Mr. Smith has set up an analogy between the example and the textbook. In the outermost rectangle, representing the interactional text, Mr. Smith, Maurice, and perhaps others are interacting, but the organization of the interactional text is not yet clear. ${ }^{3}$

Because it doubles the roles played by Mr. Smith and Maurice, discussion of the denotational content of the example has the potential to spill over into the classroom interaction. At Line 157, for example, Mr. Smith says, "now we all know Maurice and I have ha(hh)d arguments all year." Everyone in the class knows that Mr. Smith and Maurice have had a strained relationship. Mr. Smith holds students to a relatively rigid code of conduct, and Maurice has resisted this all year. Most of the female students have behaved as Mr. Smith wants, while most of the male students have withdrawn and resisted participating. Maurice, however, wants both to participate in academic discussions and to maintain his status as a male by resisting Mr. Smith's demands. Thus they have struggled with each other all year. As denoted in Line 157, and as indexed by his you'll love this at Line 148, Mr. Smith recognizes his ongoing struggle with Maurice. He mentions it at this point because he also recognizes that the example may have implications for their relationship. It gives Maurice the opportunity, within the example, to express his anger at Mr.-Smith-the-teacher. Maurice takes this opportunity by imagining that he would leave Mr.-Smith-the-tyrant to be killed.

As the discussion proceeds, Maurice enacts this participant example. That is, the metadiscourse that identifies his hypothetical character in the denotational text also comes to identify Maurice himself in the interactional text. While discussing the participant example Mr. Smith and Maurice both represent and enact parallel metadiscourses that identify Maurice as caught between those in power and those who resist.

In the example, Mr. Smith asks Maurice whether he would take Mr. Smith's side. Would Maurice-the-potential-informer become part of a we, with Mr.-Smith-the-tyrant, or would he become part of they-the other students who are opposed to Mr.-Smiththe-tyrant? This issue-which is central to the denotational text of the examplebecomes central to the interactional text as well. It becomes clear, in the next segment and elsewhere, that Mr.-Smith-the-teacher would also like Maurice-the-student to side with him. Thus Maurice gets put in the same interactional position that the text describes for Cicero. He must choose either to ally himself with those in power or to affiliate with the opposition. This position becomes uncomfortable for Maurice, as it was for Cicero. Maurice-the-potential-informer's decision not to tell Mr.-Smiththe-tyrant about the plot, within the example, has consequences for Maurice-thestudent.

We can see this in the following segment:

T/S: well that was my next question, do you think Caesar was
T/S: Caesar was a tyrant.
ST?: no
MRC: yes

T/S: then what's his pooblem. if the man- you just told me

190 point blank [ that we could be pushed down stairs

MRC: [so. 
T/S: and you wouldn't feel a thing about it. what's his big deal, if he believes Caesar is a tyrant, so what.

195

MRC: well- he- if uh he [ 4 syll ] that they're making some kind of plot against him, but he doesn't want to get involved. he doesn't know if he should get involved, he could get himself in more trouble. since he's already [ 3 syll ] =

T/S: well if Caesar's a tyrant why shouldn't you get involved. tyrants are generally dictatorial nasty people, that prevent people from being at their ease.

When Mr. Smith says, "you just told me point blank that we could be pushed down stairs and you wouldn't feel a thing about it" (Lines 189-192), both the volume and the tempo of his speech increase. He seems angry. Even though they are speaking about the example, Mr. Smith treats Maurice's choice not to tell him as a betrayal.

This starts to put the same sort of pressure on Maurice-the-student that was applied to Cicero (as described in the textbook) and to Maurice-the-potential-informer (as described in the example). Maurice's characterization of Cicero's hesitation in the face of his dilemma (at Lines 194-198) could apply to Maurice-the-student's own situation. He can tell that his answer does not please Mr.-Smith-the-teacher, but he does not seem to know what to do about it. So Maurice-the-student begins to occupy Maurice-the-potential-informer's role as it is described in the denotational text. In forcing Maurice-the-student into this position, Mr.-Smith-the-teacher also acts a bit tyrannically - thus acting out the denotational text in another respect. Figure 2 represents the discursive interaction at this point.

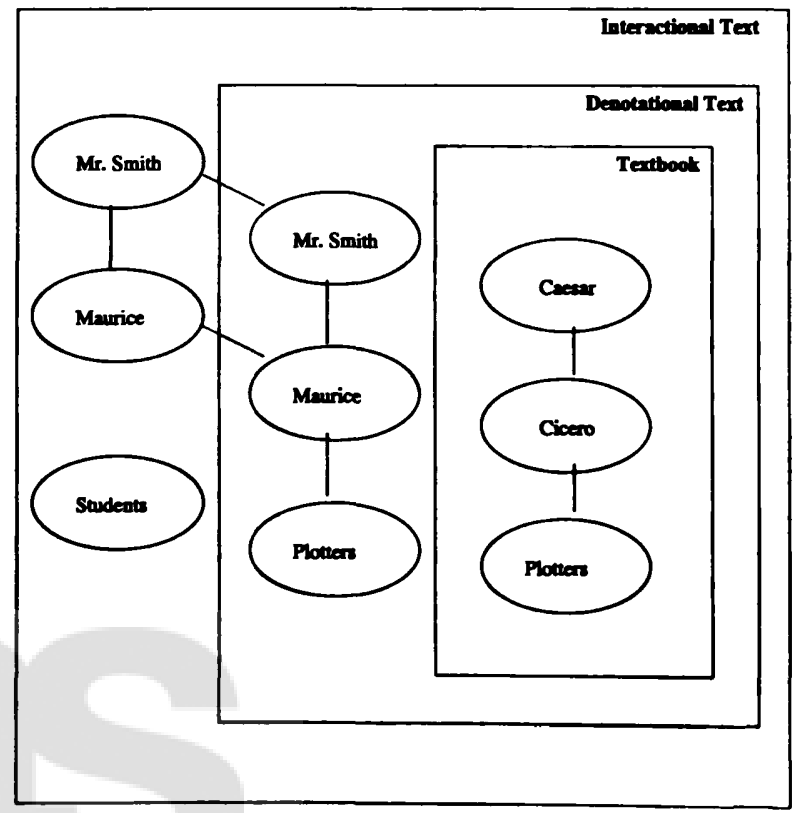


At this point, Mr. Smith may simply be playacting to involve the students. Mauricethe-student's problems become more serious, however, when several girls, and especially Candace (CAN in the example), volunteer to tell the teachers about the plot. (T/B is Mrs. Bailey, a teacher leading this classroom discussion along with Mr. Smith.)

T/S: $\quad$ gee you sound terribly confused Maurice. sort of like Cicero here.

T/B: what $w$ - if you knew that they actually you know there's a group of kids that are actually going to do:

225 this dastardly deed. and you know that there's going to be some reaction. what might you do th- and you $\mathrm{kn}$ - you know basically while you might not be- enamored totally of Mr. Smith or myself you- basically: don't wish that we were crippled for life or whatever, what

230 might you do that day. you know that's going to comethat this is all going to happen on Wednesday. what are you going to do that day.

CAN: I would try to warn you.

235 T/B:

STS: right. I would [overlapping [ comments]

[ he's- he's not- he's not

T/S: no.

T/B: what- what are you going to do that day Maurice. (1.0)

MRC: stay away. [ 2 syll ]

240 T/B: what are you going to do?

MRC: I'm going to stay away so I won't be- be:

T/B: so you're not going to come to school on Wednesday.

MRC: no

245 ST?: what would you do.

MRC: what would you do.

T/S: a coward.

CAN: yeah 'cause he's scared.

When Candace calls Maurice a coward (at Line 244), she begins to speak as Candace-the-student. Her energetic tone here indicates that she is not only elaborating the example, but also picking on Maurice-the-student. This establishes another group in the interactional text-Candace and the girls (several of whom subsequently take her side)—who position themselves with respect to Maurice and the teachers. Like their characters in the example, in the classroom the girls affiliate with the teachers and exclude Maurice.

Gender plays an important interactional role here, as it had all year in this ninthgrade classroom. Girls and boys generally occupied separate, often antagonistic groups. The girls typically had more latitude to affiliate with teachers. The boys acted more oppositionally toward teachers and risked losing face if they did not. Thus at Lines 233 and following, the girls have intensified Maurice-the-student's predicament in the interactional text. He might like to affiliate with Mr.-Smith-the-tyrant-and thus implicitly with Mr.-Smith-the-teacher-since he has aroused Mr.Smith-theteacher's anger by distancing himself. But to do so he would have to affiliate with both the teachers and the girls. This would damage his standing with the other boys. 


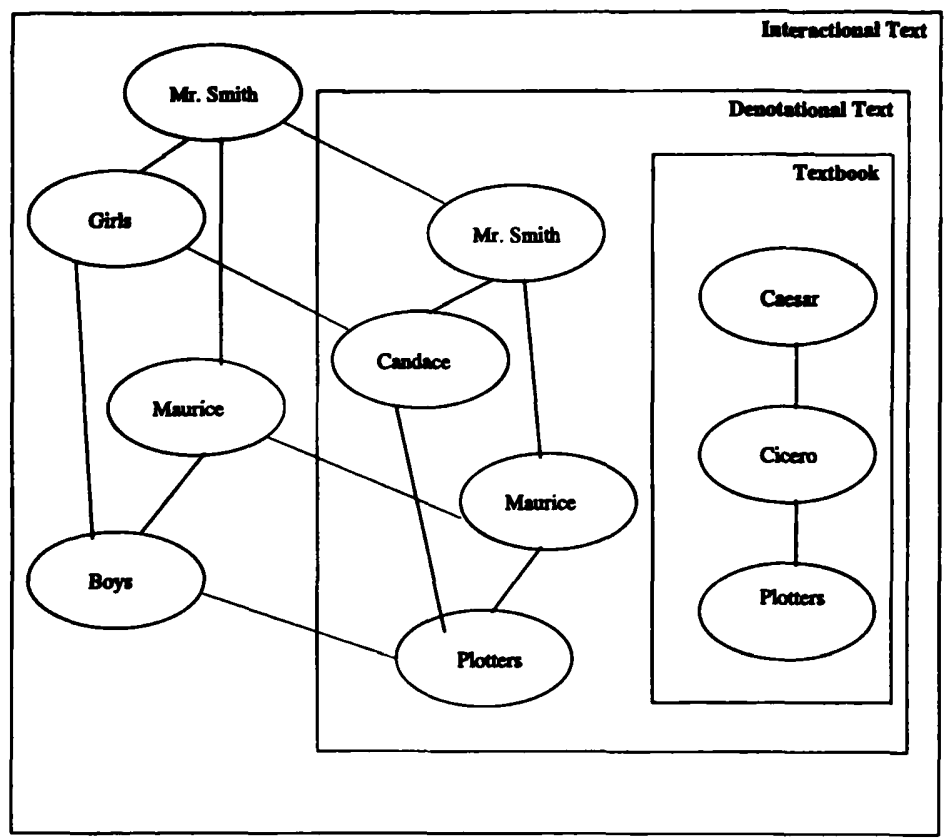

Figure 3

The enacted example in the classroom.

Thus Maurice-the-student enacts the dilemma confronted by Cicero and by Maurice-the-potential-informer. Like them, Maurice-the-student is excluded by the other groups as he thinks about what to do. In this way the denotational text and the interactional text run parallel. Figure 3 represents the parallelism.

In both the denotational and interactional texts, Maurice gets caught in the middle and Mr. Smith-the-teacher acts like a tyrant. Interactional structure described in the textbook is described in a participant example, then acted out in the interaction among teachers and students. The teachers and the girls use similar metadiscourses to frame both the denotational and the interactional texts-metadiscourses that identify Maurice as caught between those in power and those who resist.

This parallelism helps thicken Maurice's emerging identity as a student caught between the expectations of the school and the expectations of his male peers, because it provides for the robust circulation of a metadiscourse of identity. The parallelism between the metadiscourses of identity that frame the denotational and interactional texts helps maintain their consistent circulation with respect to Maurice. In fact, Maurice struggled with his in-between position throughout the academic year-stuck between his desire to participate intellectually in the class and his desire to act appropriately male. I have both ethnographic and discourse-analytic data on Maurice across the year-including several other participant examples that involved denotational and interactional parallelism and the same in-between position-showing his identity consistently being framed by this complex metadiscourse of identity. Neither he nor the other participants ever denoted his predicament explicitly, but they regularly 
oriented to this metadiscourse of identity as they positioned him in classroom interactions. The ritualized parallelism in enacted participant examples helped maintain the consistent circulation of this metadiscourse across events that include Maurice. Maurice's identity as someone caught between the teachers and the boys was produced in part through such parallelism.

\section{Enacted Autobiographical Narrative}

Autobiographical narratives are a second type of participant-denoting discourse that can involve parallelism between denotational and interactional texts. Like participant examples, autobiographical narratives double the roles played by the narrator and perhaps other participants - the narrator, at least, speaks both as a denoted character and as a participant in the event of narration. This doubling can facilitate parallelism between denotational and interactional text. As described by Ochs and Capps (2001), most everyday personal narratives have much less systematic structure. But those autobiographical narratives that do have such parallelism can help produce the consistent circulation of metadiscourses of identity.

Some earlier work on autobiographical narrative has described such parallelism, but has not worked out its implications for maintaining the consistent circulation of metadiscourses. Harding (1992), for instance, describes how a Baptist minister tells an autobiographical narrative in which he invites his audience (Harding herself) to step into and, as it were, complete his story. The minister had agreed to an interview in which he discussed the Bible and Baptist doctrine. Harding describes the interactional text as partly an interview conducted by her and partly an attempt by the minister to convert her. During this interview the minister tells the tragic story of how he himself accidentally killed his own son. As Harding shows in her analysis of imagery and Bible references, this story takes the canonical form of two great biblical sacrifice stories-Abraham and Isaac, and God and Jesus.

Harding insightfully shows how the minister uses this story to set up a parallel between himself and the great biblical fathers who were willing to sacrifice their own sons. The minister alludes to three roles in the biblical sacrifice stories: a sacrificer, a sacrifice, and a beneficiary. For example, God sacrifices his son for the sake of humanity. He then describes an analogous event in which he himself accidentally killed his own son. This event, however, contains only two of the three roles established in the biblical stories. For whom did the minister sacrifice his son? Handing argues that he did it for her. It was not planned in the same way as God's sacrifice of Jesus, of course. But in the interview itself the minister tells his story in order to convert Harding. He thus turns the tragedy of killing his own son into a story of redemption. In telling the story of his tragedy and how Jesus helped him through it, he shows Harding the power of what Jesus has done in dying for all of us. In a sense, then, the minister's son died so that the minister could tell this story and offer redemption to Harding. The minister's interactional move here depends on the parallelism between denotational and interactional texts-although the parallelism is not complete, because Harding did not convert.

This case illustrates how autobiographical narration can involve parallelism between denotational and interactional text (cf. Cain 1991 for another example). Harding's minister does more than describe the sacrifice of a son. He enacts the role of sacrificer in his interaction with Harding and makes a bid to transform the interactional text 
and their relationship. Had she accepted Jesus because of his story, he would have turned the death of his son into a sacrifice, himself into a sacrificer, and Harding into the beneficiary of the sacrifice. In this case, the parallelism between denotation and enactment maintains a metadiscourse important to the social group. Harding's minister presupposes a Biblical metadiscourse, and he tries to use it to transform Harding's and his own social identities.

A similar parallelism occurs in the narrative analyzed here. This narrative was told by Jane, a woman in her fifties. Jane had responded to an ad requesting adult subjects for a psychological study. The interviewer was a female graduate student training to be a clinical psychologist, and the interview took place in a lab at a university psychology department. The autobiographical narrative, which lasted about 50 minutes, was the first component of the interview. The interviewer prompted Jane only with the request that she tell the story of her life as if it were a novel divided into chapters. See Wortham (2001) for a detailed analysis of this narrative, from which the following summary is drawn.

Jane's parents were divorced when she was six. After the divorce her mother needed to work full time and did not know what to do with her child. For some reason she went along with a recommendation to send Jane to a boarding school. Jane refers to this chapter in her life as "the institutionalization of a human being" (all quotations in the following description are taken from her narrative). She was ostracized because of her religious background. She was beaten and humiliated by the teachers. She spent four "horrendous" years there, seeing her mother only occasionally. Jane still vividly recalls the happy day on which she left this school, much as a prisoner might recall the moment of leaving jail after serving a long sentence.

Her mother took Jane out of the boarding school in order to return to her parents' home in Louisville, Kentucky. After a brief time in which Jane had trouble adjusting to her grandparents' neighborhood, Jane's mother decided to "institutionalize" her again. Her mother again took advice from someone, and she apparently did not realize the nature of the institution. Jane was sent to a boarding school for "delinquents" and "street people." She was beaten up, her belongings were stolen, and she was miserable. At age 14, she ran away from the school and "blackmailed" her mother. She called home and refused to tell her mother where she was until her mother promised not to send her back to the school. Her mother acquiesced, and the rest of Jane's adolescence was relatively uneventful.

In her early twenties Jane had what she describes as an "affair" with a man named Robert. He was from a wealthy family and eight years older than Jane. Although he was not married, neither of them expected that this relationship would last. Jane does not say why, although she does mention that she did not feel a legitimate part of the community in her grandparents' neighborhood. She and Robert did not go on dates much, but instead met in her apartment and had sex while her mother was at work. Eventually Robert moved and the relationship ended. Jane began work at a job that she liked. Then she discovered that she was pregnant.

Impending parenthood presented Jane with a choice: Would she decide to keep her baby or give it up for adoption? In light of earlier episodes in her story, this was also a choice about whether to treat her son as her own mother had treated her. 
J:

so

he:re, the end of November, beginning of December I find out that I am now four and a half months pregnant. (2.0) Robert came back to Louisville in January (1.0) it was very very cold weather, I- I met him at a hotel and we talked. and he said what are you going to do. I said I don't know. I was being heavily pressured by, society, my own thoughts, by Robert, by my mother, to give the child up. (6.0) on the night of April 5, I went into labor, went into the hospital a:nd at two o'clock in the moming on April 6, 1956- I gave birth to a- beautiful baby boy. (3.0) while I was in the hospital, I called- again by recommendation the city orphanage. (1.0) at the ti:me, there was a shortage, on good white babies. (3.0) and a very vile woman at the city orphanage, agreed to take my baby until I could make a decision. so I took my- my darling Kenny, u:m (3.0) hu::nh (4.0) [voice quivering] to the orphanage on thirteenth 375 street (3.0) and left him there for two weeks. (2.0) two of the hardest weeks of my life. (4.0) and when the two weeks were up, (3.0) I went down there, and this horrendous p- person had these papers out for me, to sign. she had a family all lined up. (1.0) there was a- (1.0) there was a shortage of- like I say they- in those days (2.0) a nice good white baby, was a- short coming a good healthy baby. [sniff] she handed me the

380 pen (2.0) but I couldn't do it. (5.0) [voice quivering, crying] I said bring me my baby. (6.0) I want you to know this woman yelled at me. (2.0) and tried to guilt-trip me. she said, how dare you do this to me I made place for your baby. I helped you out. you have to sign these papers. I said I don't have to do anything of the sort. I want my child [sniff]. and at first she refused me. and I said I want my baby. (1.0) and she:

385 practically threw a temper tantrum right there in the office of the orphanage, and was screaming at me, because she had made room for my baby and she wanted my baby. they brought- my darling baby to me: who ha:d (1.0) his skin on his feet and his legs was totally scaled. (1.0) I think they left him alone for two weeks. I mean they- you know how you're supposed to put oil on a newborn's to keep the skin protected

390 because it's tender? my child's bo:dy was, (1.0) if I hadn't known that it was dryness, it looked like it was infested with some disease. I was ever so glad that I got him out of there, got him home, bathed him, rubbed oil on his body, a:nd u:h was determined- I didn't know how I was gonna make- make it but- I wanted to have my baby. so, I would say that's chapter five. which- determined an awful lot of the rest of my life.

Jane says that she called, "again by recommendation," an orphanage (Line 371). Her use of the word recommendation, especially with again, indexes her mother's earlier experiences with the two institutions-she said earlier that her mother accepted "recommendations" about the institutions to which she sent Jane. This time, however, Jane must make the decision whether to give her own child to an institution.

In this segment of her life story Jane presents five salient social types or "voices" (Bakhtin 1981) that appeared earlier in her narrative: ineffective caregivers (like her mother), self-interested advisors (like the person who recommended her first institution, who may have had a financial stake in it), abusers (like the teachers), plus one passive and one active narrated self. In the segment just quoted, Robert speaks with the voice of a potential caregiver abdicating responsibility. He has already had his fun and left Jane, and his only response on seeing her six months pregnant with his child is "what are you going to do?' (Lines 366-367). In this segment there are also "recommenders," or self-interested advisors. Jane says that she "was being heavily pressured" to give the child up for adoption (Line 367). She does not say who actually recommended the particular orphanage, but she does list "society," Robert, and her mother as the people pressuring her to give the baby up. "Society," given eartier descriptions of her grandparents, most likely presupposes them. Robert, her mother, and her grandparents would all benefit if Jane were to choose adoption. Robert would avoid child support, and her relatives would avoid the scandal of an unwed mother in the family. So these characters all speak like the person who pressured her mother 
to institutionalize Jane. In this segment the voice of the abusive institution is represented by the "vile," "horrendous" orphanage woman (Lines 372, 376). Horrendous is a term Jane used to describe the abusers and abusive conditions in her two institutionalizations, and thus it helps establish the same voice for the orphanage woman. Like the teachers from Jane's first institutionalization, the orphanage woman is also greedy - as Jane says, "she wanted my baby" (Line 386).

So this passage about the orphanage contains the voices of ineffective caregivers, self-interested advisors, and an abusive institution. It also contains both a victimized and an assertive narrated self for Jane. Up until the pivotal section of this segment (Lines $379 \mathrm{ff}$.), Jane herself speaks in a passive, victimized voice. She tells Robert she doesn't know what to do (Line 367), and she gives in to her family's pressure and gives her child to the recommended institution. Figure 4 represents the denotational and interactional texts up to Line 379.

The figure represents Jane underneath the interviewer in the interactional text, because Jane enacts how these past experiences still deeply affect her by crying in the interview. I analyze the interactional text below.

As she did during her second institutionalization when she ran away from the institution and "blackmailed" her mother, Jane develops from passive to active in this episode. This happens in the pivotal section from Lines 379 to 386. These lines accomplish particularly rich voicing, largely because of the dense use of metapragmatic predication and quotation. Jane and the orphanage employee both speak with two distinct voices in the encounter described in these lines. At first (Lines 381-383) the orphanage woman speaks like an authority figure: she "yelled," she "tried to guilt-trip" Jane, and she said, "how dare you do this to me." These metapragmatic predications presuppose a recognizable type of speech event with characteristic voices. The woman is like a parent and Jane is like a recalcitrant teenager. In her presentation of the rest of the interaction, however, Jane-the-narrator switches the characters' voices. From Lines 383-384 Jane speaks like an adult. She is rational and even-tempered, saying, "I don't have to do anything of the sort; I want my child" in a controlled, matter-of-fact way. The orphanage woman reacts to Jane's maturity and assertiveness like a child that isn't getting what it wants: She "practically threw a temper tantrum" and "was screaming" at Jane.

The narrated encounter between Jane and the orphanage woman, then, is a reversal or a rout. Jane is treated like a child, but she responds like an adult and reduces the institution's representative to a screaming child. Figure 5 represents the denotational and interactional texts at this point.

In the narrated events Jane has asserted her rights as a parent against the prejudices of society and the evils of the institution, and she steps forward to care for her child. This reversal of her relationship with the orphanage woman is so artfully presented that the reader or hearer will likely admire Jane's resolve and perhaps even share her sense of triumph. The reversal also presupposes more widely circulating heroic metadiscourses of identity, which lend the story some of its power. Jane seems to have overcome her passive, victimized self and to have developed her active, assertive self once and for all.

A similar transformation also occurs in Jane's interactional position during this segment. Just as in the classroom participant example, in this autobiographical narrative the denotational and interactional texts run parallel. By Line 371 Jane's narrated self has yielded to pressure and accepted the recommendation to give her baby to 


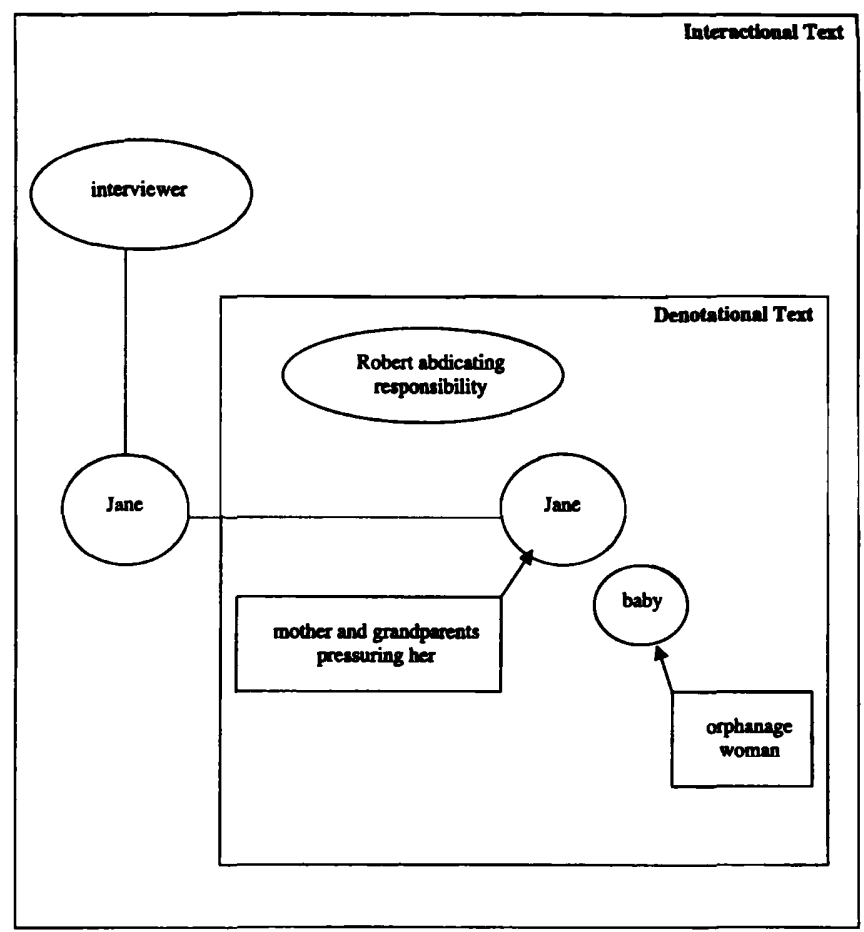

Figure 4

Jane passive at the orphanage.

the orphanage. Jane the narrator begins to position herself with respect to the orphanage woman here-clearly distancing her narrating self by describing this woman as "vile." Then Jane stops the narrative and cries. In her breakdown at Line 374 Jane enacts how much the narrated events still affect her. Thus she positions herself in the interactional text as someone who has been abused and could use some sympathy. In narrating her first institutionalization earlier in the interview, she also broke downin the full analysis I provide evidence that in the earlier segment, she interactionally positions herself as a client in search of a therapist or as a vulnerable friend in need of a sympathetic ear. Figure 4 represents this situation by placing Jane underneath the interviewer in the interactional text. She no longer dispassionately recounts her story as a piece of data.

As in the earlier episodes, however, at Line 374 the interviewer does not respond to Jane's crying at all. Jane positions herself as someone deserving of sympathy, but the interviewer does not ratify this position. Jane then returns to a more distanced interactional position. She recovers and goes on to describe how she routed the orphanage woman. While recounting this episode, Jane-the-narrator comes to speak as a competent adult in the interactional text. While describing her transformation from passive, victimized child to active, assertive adult, then. Jane's narrating self shifts from the position of a vulnerable, childlike person to the position of an active. competent adult. As the interview continues, Jane speaks in a rational, distanced way. 


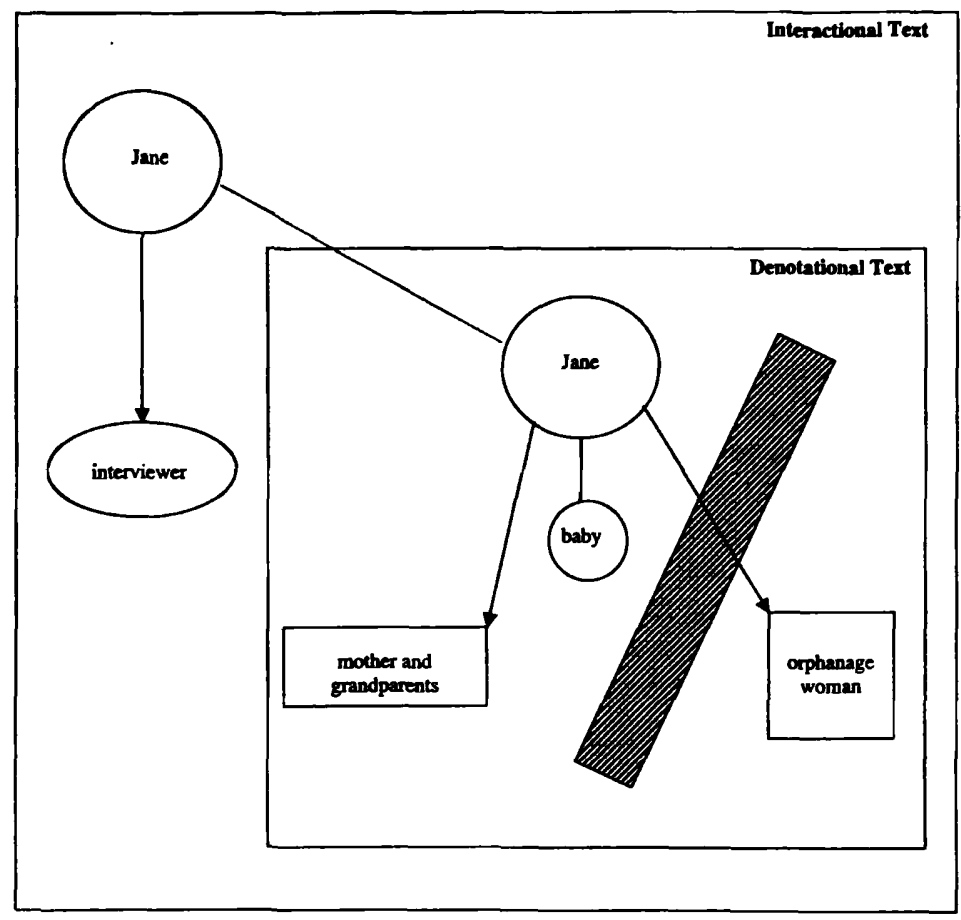

Figure 5

Jane takes control at the orphanage.

At Line 394, for instance, she voluntarily identifies the "chapter" of her life story that she has been discussing. This term indexically presupposes that the discursive interaction is once again a dispassionate research interview, because the interviewer had opened the interview with a request for Jane to divide her story into "chapters."

There is parallelism across denotational and interactional texts here: Both include a two-part developmental sequence in which Jane goes from passive to active. Similar metadiscourses are used to frame both the denotational text in Jane's narrative and her own identity in the conversation with the interviewer. She describes past events in which potential caregivers abandoned her and in which she was either abused or found the strength to take control of her own life. In the orphanage segment, for instance, she broke out of the interactional position characteristic of her mother and began to act as an assertive adult. In the interview situation itself, Jane finds herself in a similar position. She recounts difficult and emotional events, and she breaks down. The person available to support her (the interviewer) refuses. In the interactional text, then, the interviewer enacts the role of absent caregiver. Jane must go on to recover her active voice by herself. As she does so, Jane recreates the transition from passive to active in the interactional text. (Later in the interview Jane more actively asserts herself against the interviewer, making the parallelism even more robustcf. Wortham 2001.) 
Jane's identity by the end of this interview, then, is that of an active, assertive woman who has developed from an earlier passive, vulnerable self. We might interpret Jane's life story as an explanation of how she came to be this mature, active self. She passively endured abuse during her early life, but after claiming her son she has become the mature woman we see in the interview. While perhaps partly true, however, this explanation does not suffice. We cannot conclude that Jane-thenarrator is describing how a past passive, vulnerable self has been transformed into a mature, active one because this would not explain her several enactments of the passive, vulnerable self in the interview. In both the past and the present, Jane oscillates between more passive and more active selves. She both describes and enacts these selves. The same two-part developmental metadiscourse comes to frame Jane's identity in both the denotational and the interactional texts. Instead of explaining how she became active and assertive, Jane instead reenacts the developmental transition in this and (one suspects) other events. If this event is representative, she is someone who is developing over and over, not someone who has developed once and for all.

The parallelism between representation and enactment in Jane's autobiographical narrative helps establish the consistent circulation of this complex identity. The transition from passive to active presupposes a widely circulating metadiscourse of identity, one that involves a developmental transformation. This metadiscourse comes to organize the interaction between Jane and the interviewer reflexively, as a pattern of indexical cues comes collectively to presuppose that Jane has in fact developed in the interaction from passive to active. As in the case of Maurice, the parallelism between denotational and interactional texts may strengthen the power that this ritualized event has to stabilize or thicken Jane's identity - by stabilizing the circulation of this developmental metadiscourse of identity. Jane's story illustrates how autobiographical narrative can be another sort of ritualized participant-denoting discourse in which denotational and interactional parallelism can help produce stability in an individual's social identification.

\section{Conclusion}

When I did each of these studies on participant examples and autobiographical narrative, I interpreted the parallelism between denotational and interactional texts as a striking but isolated occurrence. The recurrence of this pattern in such different genres, however, and the similar parallelism described elsewhere (e.g., Cain 1991; Harding 1992; Parmentier 1997), suggests that there may be a more general process at work. This article has argued that such parallelism in participant-denoting discourse can contribute to the process of social identification.

In order for an individual to be socially identified, processes at three time scales must interact. Circulating sociocultural categories of identity must be taken up into the ontogenetic trajectory of an individual, such that a recognizable category comes consistently to identify that individual across many interactional events of social identification. Each of these three processes depends on the others: Sociocultural categories of identity exist only through the individuals whom they identify and the events in which they actually circulate; individuals' developing identities become recognizable only through sociocultural categories and exist empirically only in actual events; and events of social identification presuppose both sociocultural categaries and individuals to be identified. 
Both analysts and participants generally take for granted that these three processes work in concert, assuming that a given sociocultural category "naturally" characterizes an individual over time and in a focal event. But in fact there are serious indeterminacies at all three levels. Many sociocultural categories potentially circulate through any individual's life and any given event-in most events, individuals could turn out to be various different kinds of people. Given this indeterminacy, taken-for-granted social identification must be an accomplishment. What explains the stabilization of social identification, such that it can seem natural?

This article has described participant-denoting discourse as one mechanism through which social identification can be stabilized - that is, a device that helps keep a category of social identity circulating consistently through events involving a particular individual. Some participant-denoting speech events, like participant examples and autobiographical narratives, can involve parallelism between how participants describe themselves and how they position themselves (or get positioned) in the event of speaking. This sort of parallelism between denotational and interactional texts identifies certain participants both denotationally and interactionally with the same metadiscourses or categories of identity. Being consistently and simultaneously identified at both these levels, especially when such ritualized events are repeated over time, can stabilize an individual's social identity by helping establish the consistent circulation of certain sociocultural categories across the individual's ontogenetic trajectory.

This conclusion needs to be qualified in two important ways. First, the sort of parallelism across denotational and interactional texts that occurs in some participantdenoting discourse cannot be sharply distinguished from the sort of mapping that almost always occurs across these two layers in any discursive interaction. Irvine (1996), Silverstein (1997), and others describe how denotational and interactional texts are mapped into each other even in discursive interactions that involve less extensive parallelism. We should envision a continuum of parallelism, from cases with little or none up through extensive, ritual-like ones. The cases of participantdenoting discourse described in this article lie closer to the ritual end of the continuum, but they are not qualitatively distinct from all other discursive interaction. Second, identity is not maintained only in participant-denoting discourse. Individuals get positioned in all kinds of verbal and nonverbal interaction, and for particular individuals nonparticipant-denoting and nonritualized discourse is often crucial to maintaining or transforming identity. Such parallelism in participant-denoting discourse can nonetheless play an important role in social identification, and it deserves more empirical investigation.

\section{Notes}

1. Ritualized events, like habitual greetings, lie on a continuum with formal ritual ones. Though smaller in scale, they can accomplish similar effects (Bell 1997; Parmentier 1997). Chunks of culture get packaged in ritualized events, such that they circulate more consistently.

2. Discursive interactions with such denotational and interactional parallelism generally involve both reportive and reflexive calibration. The denotational text is often reportively calibrated, with participants saying explicitly what they are doing. The interactional text is generally reflexively calibrated. Despite the denotational text's de facto status as a statement of the metadiscourse that comes to frame the interaction, participants normally do not consciously perceive or explicitly note the parallelism between denotational and interactional 
texts. They orient to the metadiscourse organizing the interactional text, mostly on the basis of indexical cues. But the presence of an analogous denotational text reinforces that metadiscourse, providing more structure than occurs in typical discursive interactions.

3. Space limitations prevent a full description of the analyses summarized in the next two sections of this article. See Wortham $(1994,2001)$ for more detailed analyses of these data and more extended descriptions of the methodological approach.

\section{References Cited}

Agha, Asif

In press Language and Social Relations. New York: Cambridge University Press. Bakhtin, Mikhail

1981 [1935] Discourse in the Novel. Caryl Emerson and Michael Holquist, trans. In The

Dialogic Imagination. Pp. 259-422. Austin: University of Texas Press.

Bateson, Gregory

1972 Steps to an Ecology of Mind. New York: Ballantine.

Bell, Catherine

1997 Ritual: Perspectives and Dimensions. New York: Oxford University Press.

Bickhard, Mark, and John Christopher

1994 The Influence of Early Experience on Personality Development. New Ideas in

Psychology 12:229-252.

Bourdieu, Pierre

1977[1972] Outline of a Theory of Practice. Richard Nice, trans. New York: Cambridge University Press.

1998[1994] Practical Reason. Richard Nice, trans. Stanford: Stanford University Press.

Cain, Carole

1991 Personal Stories. Ethos 19:210-253.

Cole, Michael

1996 Cultural Psychology. Cambridge, MA: Harvard University Press.

Csordas, Thomas

1994 The Sacred Self. Berkeley: University of California Press.

2002 Body/Meaning/Healing. New York: Palgrave Macmillan.

Dreyfus, Hubert, and Paul Rabinow

1993 Can There Be a Science of Existential Structure and Social Meaning? In Bourdieu:

Critical Perspectives. Craig Calhoun, Edward LiPuma, and Moishe Postone, eds.

Pp. 35-44. Chicago: University of Chicago Press.

Du Bois, John

1986 Self-Evidence and Ritual Speech. In Evidentiality. Wallace Chafe and Johanna

Nichols, eds. Pp. 313-336. Norwood, NJ: Ablex.

Durkheim, Emile

1965[1915] The Elementary Forms of the Religious Life. New York: Free Press.

Goffman, Erving

1974 Frame Analysis. New York: Harper and Row.

Hanks, William

1993 Notes on Semantics in Linguistic Practice. In Bourdieu: Critical Perspectives.

Craig Calhoun, Edward LiPuma, and Moishe Postone, eds. Pp. 139-155. Chicago:

University of Chicago Press. 
Harding, Susan

1992 The Afterlife of Stories. In Storied Lives. George Rosenwald and Richard Ochberg, eds. Pp. 60-75. New Haven: Yale University Press.

Hill, Jane, and Judith Irvine, eds.

1992 Responsibility and Evidence in Oral Discourse. New York: Cambridge University Press.

Holland, Dorothy, and Jean Lave, eds.

2001 History in Person. Santa Fe: School of American Research Press.

Hymes, Dell

1996 Ethnography, Linguistics, Narrative Inequality. Washington, DC: Taylor and Francis.

Irvine, Judith

1996 Shadow Conversations: The Indeterminacy of Participant Roles. In Natural Histories of Discourse. Michael Silverstein and Greg Urban, eds. Pp. 131-159. Chicago: University of Chicago Press.

Jakobson, Roman

1960 Closing Statement: Linguistics and Poetics. In Style in Language. Thomas Sebeok, ed. Pp. 350-377. Cambridge, MA: MIT Press.

Kratz, Corinne

1994 Affecting Performance. Washington, DC: Smithsonian Institution Press.

Kulick, Don

2000 Gay and Lesbian Language. Annual Review of Anthropology 29:243-285.

Lemke, Jay

2000 Across the Scales of Time. Mind, Culture and Activity 7:273-290.

Malinowski, Bronislaw

1935 Coral Gardens and Their Magic. London: Allen and Unwin.

McLaren, Peter

1986 Schooling as Ritual Performance. Boston: Routledge and Kegan Paul.

Merleau-Ponty, Maurice

1962 Phenomenology of Perception. Colin Smith, trans. New York: Macmillan.

Ochs, Elinor, and Lisa Capps

2001 Living Narrative. Cambridge, MA: Harvard University Press.

Parmentier, Richard

1997 The Pragmatic Semiotics of Cultures. Semiotica 116:1-115.

Rampton, Ben

2002 Ritual and Foreign Language Practices at School. Language in Society 31(4):491-526.

Silverstein, Michael

1976 Shifters, Linguistic Categories, and Cultural Description. In Meaning in Anthropology. Keith Basso and Henry Selby, eds. Pp. 11-55. Albuquerque: University of New Mexico Press.

1985 On the Pragmatic "Poetry" of Prose. In Meaning, Form and Use in Context. Deborah

Schiffrin, ed. Pp. 181-199. Washington, DC: Georgetown University Press.

1992 The Indeterminacy of Contextualization: When is Enough Enough? In The Contextualization of Language. Aldo DiLuzio and Peter Auer, eds. Pp. 55-75. Amsterdam: John Benjamins.

1993 Metapragmatic Discourse and Metapragmatic Function. In Reflexive Language. John Lucy, ed. Pp. 33-58. New York: Cambridge University Press.

1997 The Improvisational Performance of "Culture" in Realtime Discursive Practice.

In Creativity in Performance. Keith Sawyer, ed. Pp. 265-312. Norwood, NJ: Ablex. 
Silverstein, Michael, and Greg Urban, eds.

1996 Natural Histories of Discourse. Chicago: University of Chicago Press.

Taylor, Charles

1991 The Dialogical Self. In The Interpretive Turn. David Hiley, James Bohman, and

Richard Shusterman, eds. Pp. 304-314. Ithaca, NY: Cornell University Press.

Urban, Greg

1996 Metaphysical Community. Austin: University of Texas Press.

2001 Metaculture: How Culture Moves through the World. Minneapolis: University of Minnesota Press.

Wittgenstein, Ludwig

1953 Philosophical Investigations. 3rd edition. G. E. M. Anscombe, trans. New York:

Macmillan.

Wortham, Stanton

1994 Acting Out Participant Examples in the Classroom. Philadelphia: John Benjamins.

1997 Denotationally Cued Interactional Events: A Special Case. Semiotica 114:295-317.

2001 Narratives in Action. New York: Teachers College Press.

University of Pennsylvania

Graduate School of Education

3700 Walnut Street

Philadelphia, PA 19104-6216

stantonw@gse.upenn.edu

\section{Appendix A}

Transcription Conventions:

- abrupt breaks or stops (if several, stammering)

? rising intonation

. falling intonation

- (underline) stress

(1.0) silences, timed to the nearest second

[ indicates simultaneous talk by two speakers, with one utterance represented on top of the other and the moment of overlap marked by left brackets

= interruption or next utterance following immediately, or continuous talk represented on separate lines because of need to represent overlapping comment on intervening line

[...] transcriber comment

: elongated vowel

, pause or breath without marked intonation

(hh) laughter breaking into words while speaking 